Original Article

\title{
ANTI-ASTHMA ACTIVITY OF TAMARIND PULP EXTRACT (TAMARINDUS INDICA L.)
}

\author{
RIFA'ATUL MAHMUDAH'*, I KETUT ADNYANA², NENGFISHERI KURNIA²
}

${ }^{1}$ Department of Pharmacy, Mandala Waluya Institute of Health Sciences, Kendari, Indonesia, ${ }^{2}$ Pharmacology-Clinical Pharmacy Research Group, School of Pharmacy, Bandung Institute of Technology, Bandung, Indonesia Email: ifamahmudah11@gmail.com

Received: 02 Jan 2017, Revised and Accepted: 31 Apr 2017

\section{ABSTRACT}

Objective: Tamarind (Tamarindusindica L.) is one of the plants, which most of its parts are not only rich in nutrients, but also has been used widely in the community as a medicine, and one of them is believed to have effectiveness as anti-asthma.

Methods: The study of that anti-asthma activity was conducted by using the test method of improvement breathing patterns in the male guinea pig and using anti-inflammatory testing in male Wistar rats.

Results: The results of breathing patterns improvement test shows that there is no significant difference of breath intensity between observation groups (extract in doses of $25 \mathrm{mg} / \mathrm{kg}$ bw guinea pig, $75 \mathrm{mg} / \mathrm{kg}$ bw guinea pig, and $225 \mathrm{mg} / \mathrm{kg}$ bw guinea pig) and the control group. However, it has significant differences $(\mathrm{p}<0.05)$ in the decline of breath frequency, in line with the effect that given by methylprednisolone 4.5 mg/kg bw guinea pig and salbutamol $4 \mathrm{mg} / \mathrm{kg}$ bw guinea pig. While the result of anti-inflammatory test shows the significant decrease in inflammation percentage in each of observation group (extract in doses of $25 \mathrm{mg} / \mathrm{kg}$ bw rat, $75 \mathrm{mg} / \mathrm{kg}$ bw rat, and $225 \mathrm{mg} / \mathrm{kg}$ bw rat) than the control group at minute 30 up to 360 , it is in line with the reduction effect given by methylprednisolone $4.5 \mathrm{mg} / \mathrm{kg}$ bw rat.

Conclusion: The best effect in breathing patterns improvements and anti-inflammatory are demonstrated by extract in a dose of $75 \mathrm{mg} / \mathrm{kg}$ bw. One of the anti-asthma mechanisms is an anti-inflammatory effect.

Keywords: Tamarindusindica L., Anti-asthmatic, The improvement of breathing pattern, Anti-inflammatory

(C) 2017 The Authors. Published by Innovare Academic Sciences Pvt Ltd. This is an open access article under the CC BY license (http://creativecommons.org/licenses/by/4.0/) DOI: http://dx.doi.org/10.22159/ijcpr.2017v9i3.19968

\section{INTRODUCTION}

Asthma is chronic respiratory diseases that still become one of the problems in the world, with an estimated that 300 million people suffer it [1]. This disease is characterised by symptoms of a cough, wheezing, and chess tightness. These symptoms may occur continuously, episodic, seasonally, or when in contact with triggers. Symptoms may occur more frequently at night, early in the morning, or when doing physical activity [2]. Typical strages that will occurin asthma when exposed to an allergen, such as induction phase, early phase asthmatic reaction, and late phase asthamatic reaction [3]. History of atopic disease in a patient or family strengthens the case of asthma [4].

The prevalence of asthma in Africa, Latin America, Eastern Europe and Asia continues to increase. The World Health Organization Global Burden of Disease Study estimated that almost 13.8 million of disabilityadjusted life years (DALYs) lose each year because of asthma, which represents $1.8 \%$ of the total global disease burden. It is also estimated that asthma caused 346,000 deaths worldwide each year [1]. In Indonesia, the prevalence of asthma in 2013 reached $4.5 \%$. The highest of the prevalence of asthma was found in Central Sulawesi (7.8\%), followed by East Nusa Tenggara (7.3\%), DI Yogyakarta (6.9\%), and South Sulawesi $(6.7 \%$ ) [5]. While the results of the ISAAC(International Study on Asthma and Allergy in Children) questionnaire showed that prevalence of asthma in 2000-2003 at the age of 13-14was 2.6\% [1].

According to its characteristics, the prevalence of asthma increases as long as people grow up and begin to decrease by the age of $\geq 45$. In women, the prevalence is likely to be higher than in men with the same number of events seen between urban and rural areas [5].

Nowadays, the asthma drugs are divided into two major groups, namely, reliever and controller. The reliever is a drug that quickly eliminates the symptoms of asthma (airway obstruction), while the controller is a medication that is used to control persistent asthma. Drugs belonged to reliever are beta- 2 agonists, anticholinergics, theophylline, and systemic corticosteroids. While a drug that belonged to the controller group is anti-inflammatory medications such as corticosteroids, sodium cromoglycate, nedocromil sodium, antihistamines and slow action. However, those drugs do not only provide efficacy but also have side effects that are not small [4].

Tamarindusindica L. is one of the plants that each of its part, both its roots, stems, fruits, and leaves are not only rich in nutrient levels such as tartaric acid, acetic acid, citric acid, formic acid, malic acid, and succinic acid [6]. But also has already used widely as a drug. Several uses of Tamarindusindica L. as traditional medicines area digestive and as a treatment for digestive, biliary disease, antisorbutic, anti-inflammatory, throat pain, rheumatism, and breating problems, wound healing, abdominal pain, diarhea, dysentery, parasitic infections, fever, malaria [7-9]. This study aims to determine the anti-asthma activity of Tamarindusindica L. fruit pulp with water extracts. Thus, that way of extractsis expected to be easier for the public and the effectiveness of its use can be justified.

\section{MATERIALS AND METHODS}

\section{Instrument}

Evaporator, chamber, funnel, Erlenmeyer, freeze-dry, watch glasses, beakers, measuring cups, syringes no.27, guinea pig cage, rat cage, cotton, weighing paper, filter paper, electric stove, UV lamps $\lambda 254$ and $366 \mathrm{~nm}$, silica gel GF254 plate, mortar and stamper, oppo R821 microphone, oven, water bath, tweezers, pipette, pletismometer, Cool edit pro 2.1 programs, tube rack, a set of reflux, $1 \mathrm{ml}$ and $5 \mathrm{ml}$ syringe, rat oral sonde, test tubes, animal scales, analytical balance, aerosol containers, guinea pigs containers, and the vial.

\section{Ingredients}

Amyl alcohol, ammonia 25\%, distilled water, hydrochloric acid $2 \mathrm{~N}$, concentrated hydrochloric acid, sulphuric acid, iron (III) chloride $1 \%$, CMC Na., Dragendorff reagent, Buchard-Libermann reagent, Mayer reagent, salbutamol $4 \mathrm{mg}$, gelatin powder, magnesium powder, Tamarindusindica L. pulp. 


\section{Collection of sample}

Tamarindusindica L. pulp was extracted by using reflux way with distilled water as a solvent. The extract obtained was frozen and dried to get extract powder.

\section{Animals}

Adult male wistar rats of 2-3 mo old, weighing about 150-200 grams were obtained from the Animal Laboratory of the School of Pharmacy, Institute of Technology Bandung (ITB). Adult male guinea pigs of 4-5 mo old, weighing about 400-600 grams were obtained from Lembang-Bandung.

\section{Preparation of plant extract}

Tamarindusindica L. pulp was extracted by using reflux with distilled water as a solvent. The extract obtained was frozen and dried to get extract powder.

\section{Testing of breathing pattern improvement}

In the testing of breathing pattern improvement, male guinea pigs were divided into 6 groups, positive control (CMC Na 0.3\%), the comparison group 1 (Methylprednisolone $4.5 \mathrm{mg} / \mathrm{kg} \mathrm{bw}$ ), the comparison group 2 (Salbutamol $4 \mathrm{mg} / \mathrm{kg} \mathrm{bw}$ ), the extract group of $25 \mathrm{mg} / \mathrm{kg} \mathrm{bw}$, the extract group of $75 \mathrm{mg} / \mathrm{kg} \mathrm{bw}$, and the extract group of $225 \mathrm{mg} / \mathrm{kg} \mathrm{bw}$.

Guinea pigs had fasted for about \pm 18 hours**. Then the respiratory pattern of each group of guinea pigs was initially recorded for about \pm 2 min by using Cool Edit Pro 2.0 program. Induction was given in the form of aerosol histamine dihydrochloride $0.4 \mathrm{ml}$ of $0.1 \%$ sprayed on the container of guinea pigs, then it was recorded again for $5 \mathrm{~min}$ to see the effect of induction. Comparator drug delivery and test materials were orally administered 30 min later. Then the pattern of breathing was recorded after $30 \mathrm{~min}$ for $2 \mathrm{~min}$, and they have induced again, then the pattern of breathing was recorded for $5 \mathrm{~min}$. The assessment of the breathing pattern improvement of marmot was seen by frequency sound waves $(\mathrm{Hz})$ and intensity of loudness (dB) [10].

The data obtained were then processed using the statistical method, ANOVA, and Tukey HSD post hoc analysis using SPSS Statistics 20. The obtained results were compared to the positive control group to see the improvement effect of the breathing pattern of Tamarindusindica L.

\section{Testing of anti-inflammatory activity}

In testing the anti-inflammatory, the tested animals in the form of male Wistar rats were divided into 5 groups, namely the positive control (CMC-Na 0.3\%), the comparison group (Methylprednisolone $4.5 \mathrm{mg} / \mathrm{kg} \mathrm{bw}$ ), group extract $25 \mathrm{mg} / \mathrm{kg} \mathrm{bw}$, the extract group 75 $\mathrm{mg} / \mathrm{kg} \mathrm{bw}$, and extract group $225 \mathrm{mg} / \mathrm{kg}$ bw.
Animal tests were fasted for \pm 18 hours**. Then the hind legs of each of rats were given a sign and initial volume of their feet (V0) was measured by using the pletismometer. Each foot of rats was injected inducers such as histamine dihydrochloride $0.1 \% \mathrm{w} / \mathrm{v}[11,12]$ as much as $0.05 \mathrm{ml}$ by intra-plantar [12]. After $30 \mathrm{~min}$, each rat was given the test preparation based on the group (positive control, the comparison group, or a group of extracts of various doses). Then, every 30 min of 6 hours** and on the hour24, rat foot volume was measured again by using pletismometer. The foot volume for each measurement was recorded as a volume at time $\mathrm{t}(\mathrm{Vt})$ [13].

The percentage inhibition of edema was calculated using the following equation:

$$
\% \text { Inhibition of Inflammation }=1-\frac{V t}{V_{e}} \times 100 \%
$$

$\mathrm{Vt}=$ average foot volume of test group

$\mathrm{Vc}=$ average foot volume of control group [13, 14].

The data obtained than were processed using the ANOVA statistical method and Tukey HSD post hoc analysis using SPSS Statistics 20. The obtained results were compared to the positive control group to see the improvement effect of the breathing pattern of Tamarindusindica $\mathrm{L}$.

\section{RESULTS AND DISCUSSION}

\section{Phytochemical screening}

Phytochemical screening of the Tamarindusindica L. pulp shows the presence of flavonoid, tannin, and saponin.

\section{Effect of repair breathing pattern}

Reseach on Anti-Asthma Activity of Tamarind pulp extract (Tamarindus indica L.)used 2 methods of testing, testing repair activity breathing patterns and testing anti-inflammatory activity. Both methods have been based on the causes of asthma include swelling (inflammation) in the area of the airways (bronchi) that causes bronchoconstriction, so breathing becomes obstructed [1].

In testing the activity patterns of use breath improvement program Cool Edit Pro 2.0 performed observations of intensity (dB) and frequency $(\mathrm{Hz})$ breathing guinea pigs in various circumstances. Frequency is the amount of vibrations per second. High or low sound frequencies assigned by the units of sound expressed in Hertz $(\mathrm{Hz})$. While the intensity is a ratio of voltage and voltage noise that comes standard sound that can be heard by humans with normal hearing at frequencies of $1000 \mathrm{~Hz}$, expressed in decibels (dB) [15].

In the state of asthma, respiratory intensity becomes higher than the intensity of the normal breathing, while the frequency can be more or less than in normal breathing.

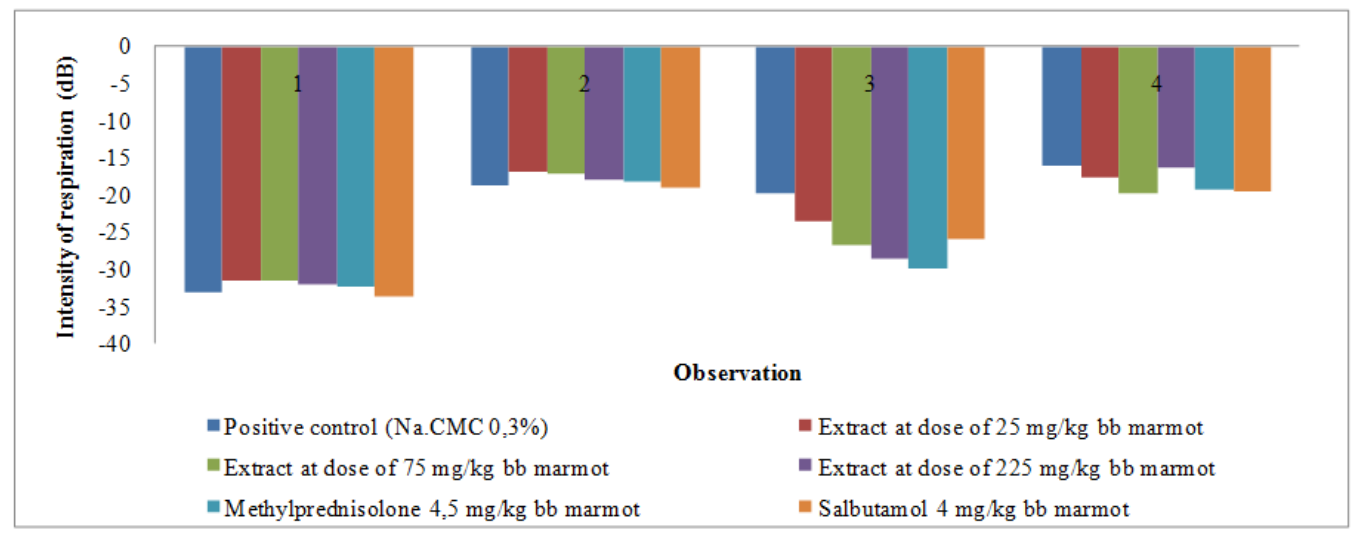

Fig. 1: Comparison of decreasing intensity of respiration of guinea pigs at various test groups. Significant differences $* p<0.05$ compared with the positive control group (one-way ANOVA with post hoc Tukey test). 1) Observation of normal conditions ( 2 min); 2 ) The observation after induced of aerosol histamine dihydrochloride $0.1 \%$ ( $5 \mathrm{~min})$; 3 ) $30 \mathrm{~min}$ observations after being given the test material ( $2 \mathrm{~min}$ ); 4) Observations after second induced of aerosol histamine dihydrochloride $0.1 \%$ (5 min). 


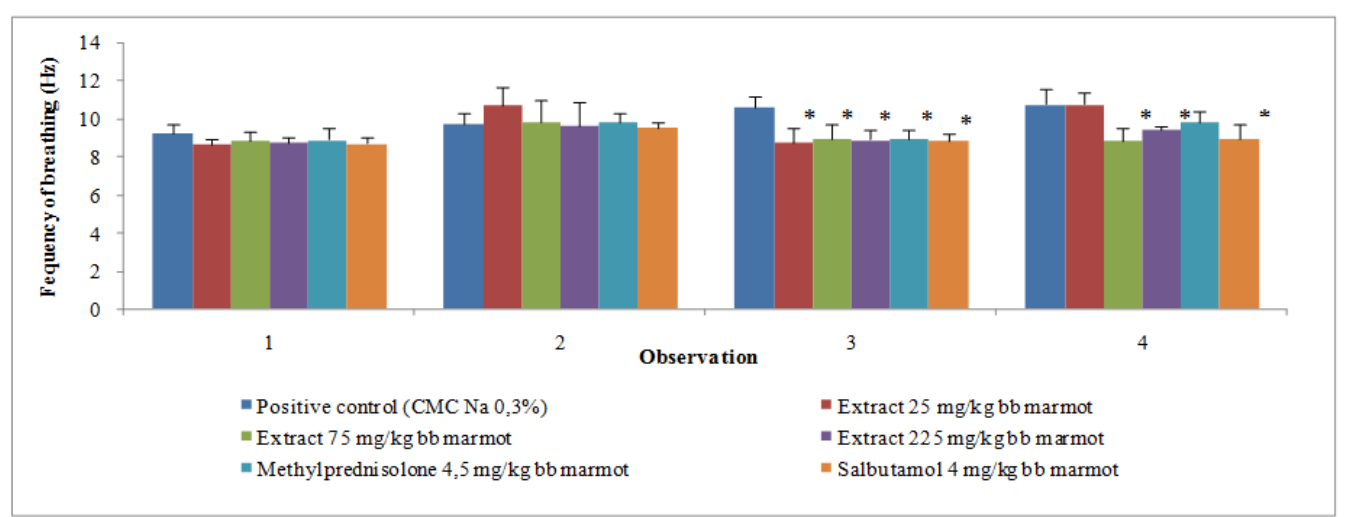

Fig. 2: Comparison of respiratory frequency of guinea pigs at various test groups. Significant differences * $\mathbf{p}<0.05$ compared with the control group (one-way ANOVA with post hoc Tukey test). 1) Observation of normal conditions (2 min); 2) The observation after the induced of aerosol histamine dihydrochloride $0.1 \%(5 \mathrm{~min}) ; 3) 30$ min observations after being given the test material (2 min); 4) Observations after second induced of aerosol histamine dihydrochloride $0.1 \%(5 \mathrm{~min})$

The test recording breathing patterns marmotindicated a significant difference $(\mathrm{p}<0.05)$ between the intensity of breathing in the normal condition and the intensity of the breathing after giving first and second induction. When guinea pigs are given an induction, the intensity of breathing increased if it compared to a normal condition. While the administration of a preparation does not show significant differences to the normal condition. This result of observation indicates the successful of inducing asthma. For frequency of breathing, there are no significant differences between each of observation.

The result of observation also showed that there are no significant differences $(p<0.05)$ of the intensity of respiratory pattern between guinea pig in each test group and the positive control group. While the observation of frequency of breathing patterns indicates a significant difference $(\mathrm{p}<0.05)$ after administration of a preparation in each group of the positive control group, so it can be stated that the administration of a preparation in each treatment group has an effect, such as the improvements of breathing pattern towards the normal breathing.
Based on the symptoms shown in the condition of asthma, breathing becomes faster and hard if it compared to normal conditions. This was shown by the intensity and frequency of the breathing pattern of the guinea pig after they were given induction. Therefore, the decline after administration of the preparation shows that the preparation (the given extract) effected the improvement of the breathing pattern.

From these results, it appears that the effect of highest decrease seen in the extract $75 \mathrm{mg} / \mathrm{kg}$ bw of guinea pig, almost the same as the effect given by salbutamol $4 \mathrm{mg} / \mathrm{kg}$ bw of guinea pig, in which respiratory rate is close to normal in the delivery preparations and still persist in the administration of the second inductor.

While the anti-inflammatory activity of the test results in each group of animal tests showed a decrease over time since induction was given and it returned to normal again after 1,440 $\min \left(24 \mathrm{~h}^{* *}\right)$. However, the decreasing rate of inflammation in each group was different. The highest percentage of reduction of inflammation could be seen at a dose of $75 \mathrm{mg} / \mathrm{kg}$ bw of rats, in which it showed the normal condition in 360 min ( 6 hours ${ }^{* *}$ ).

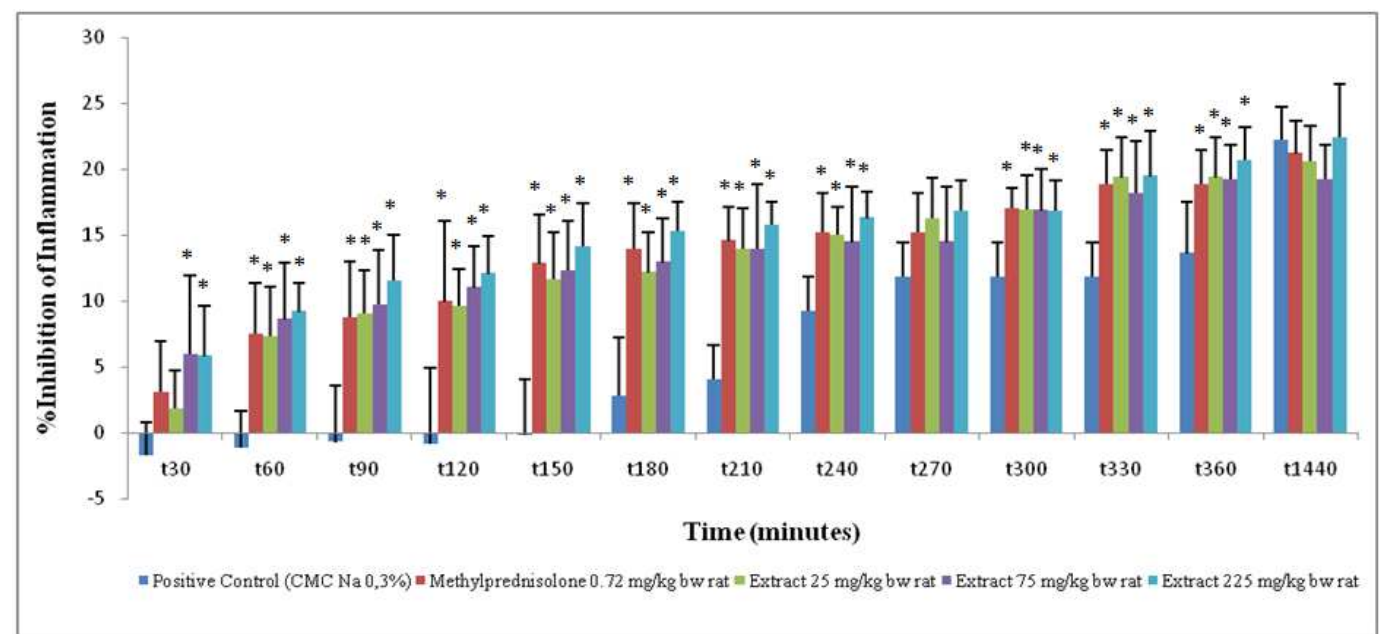

Fig. 3: Percentage of reduction of inflammation of the mice in the various test groups. Significant differences *p $<0.05$ compared with the control group (one-way ANOVA with post hoc Tukey test)

Percentage of reduction in inflammation that was analyzed by using ANOVA method with SPSS 20 post hoc Tukey program in each treatment group showed significant differences $(\mathrm{p}<0.05)$ in control group ranging from minute 30 to minute 360 , except at minute 270 . This result shows that each group that is given the test material has effectiveness on reducing inflammation.

\section{CONCLUSION}

Extract of the pulp of tamarind (Tamarindusindica L.) at doses (25 $\mathrm{mg} / \mathrm{kg}$ bw, $75 \mathrm{mg} / \mathrm{kg}$ bw and $225 \mathrm{mg} / \mathrm{kg} \mathrm{bw}$ ) gives effect to decrease the frequency of respiratory and anti-inflammatory effects in animal models of asthma that has already been induced by histamine 
dihydrochloride $0.1 \%$. The effect of improving breathing patterns and the anti-inflammatory extract is best demonstrated by a dose of $75 \mathrm{mg} / \mathrm{kg}$ bw. One mechanism of anti-asthma is through antiinflammatory effects.

\section{CONFLICT OF INTERESTS}

\section{Declare none}

\section{REFERENCES}

1. Global Initiative For Asthma. Global strategy for asthma management and prevention. National Institutes Health 2014;7-8:29-37.

2. Dipiro JT, Chisholm-Burn M, Wells BG, Schwinghammer TL, Malone PM, Kolesar JM, et al. Pharmacotherapy principal and practice. The McGraw-Hill Companies. The United States; 2008. p. 211.

3. Sari CYI. Allergic inflammation in asthma. CDK-207. Vol. 40 Faculty of Medicine, IU/Friendship Hospital. Jakarta, Indonesia; 2013. p. 586-7.

4. Mulia MJ. Development of pathogenesis and treatment of bronchial asthma. Faculty of Pharmachy. University of Trisakti. Jakarta, Indonesia; 2011. p. 6.

5. Agency for Health Research and Development. Basic health research. Ministry of Health of Indonesia. Jakarta, Indonesia; 2013. p. 86-7.

6. Meher B, Deepak KD, Anupama R. a review on: phytochemistry, pharmacology and traditional uses of Tamarindus indica L. World J Pharm Pharm Sci 2014;3:229-30, 233

7. Morton JF. The tamarind (Tamarindus indica L.) its food, medical and industrial uses. University of Miami. Florida State Horticultural Society; 1958. p. 291.
8. Kuru P. Tamarindus indica and its health-related effects. Marmara University School of Medicine, Medical Intern. Istanbul, Turkey. Asian Pacific J Trop Biomed 2014:4:677-9.

9. Iskandar Y. Medicinal plants efficacious as antibronchial asthma. Faculty of Pharmacy, Padjadjaran University. Jatinangor, Indonesia; 2006. p. 15.

10. Prasaja Y, Soemardji AA, Sigit JI. Activity anti-ashmatic of sembung (Blumea balsamifera (L.) DC.) leaves ethanol extract based on breathing patterns of male guinea pigs. Bandung Institute of Technology. Bandung, Indonesia; 2005. p. 1.

11. Bokanisereme, Yusuf UF, Okechuwu PN. Anti-inflammatory, analgesic and antipyretic activity of cassava leaves extract. Asian J Pharm Clin Res 2011:6:90.

12. Gupta M, Mazumder UK, Gomathi P, Selvan VT Antiinflammatory evaluation of leaves of Plumeria acuminate. BioMed Central Sci 2006;6:3.

13. Tayade P, Baba J, Angadi S, Chandrasekar N, Jagtap SA, Vaishnav G, et al. Antihistaminic activity of methanolic extract of leave of Tamarindus indica Linn. J Chem Pharm Sci $2009 ; 2: 274$

14. Kaushik ML, Jalalpure. Anti-inflammatory efficacy of Curcuma zedoaria ROSC. root extracts. Asian J Pharm Clin Res 2011;4:90.

15. Hidayah N, Nasution. Relations noise exposure and characteristics vespa pedicab drivers against blood pressure in padangsidimpuan city in 2013. University of Northern Sumatra. Padang, Indonesia; 2014. p. 14.

\section{How to cite this article}

- $\quad$ Rifa'atul Mahmudah, I Ketut Adnyana, Nengfisheri Kurnia. Antiasthma activity of tamarind pulp extract (Tamarindus Indica L.). Int J Curr Pharm Res 2017;9(3):102-105. 